\title{
ANALYSIS AND INTERPRETATION OF TIME- LAPSE MICORGRAVITY DATA CASE STUDY IN KOTA LAMA SEMARANG TOURISM AREA
}

\author{
Supriyadi*, Khumaedi, Sugiyanto \\ Jurusan Fisika Universitas Negeri Semarang, Sekaran Gunungpati, Semarang, Indonesia \\ *Corresponding Author Email: supriyadi@mail.unnes.ac.id
}

Received: 31 July 2020

Revised: 23 August 2020

Accepted: 22 October 2020

Online: 27 November 2020

Published: 31 December 2020

SPEKTRA: Jurnal Fisika dan Aplikasinya p-ISSN: 2541-3384

e-ISSN: 2541-3392

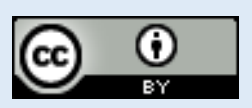

\begin{abstract}
A time-lapse microgravity survey has been carried out in the Kota Lama (Semarang, Indonesia) tourism area. The survey in question is to measure gravity at the same point repeatedly with a specific time interval, in this case, conducted in January 2019 and July 2019. Measuring gravity is carried out at as many as 75 points that are spread evenly at the survey location. The instrument used is a Scintrex CG5 type gravimeter and GPS to determine the latitude and the longitude of each measuring point. The measurement results after being corrected, namely the Apungan and the Appeal correction, obtained the observational gravity $\left(\mathrm{g}_{\mathrm{ob}}\right)$ in the January 2019 period showing that a minimum of $978118.44 \mathrm{mGal}$ and a maximum gravity of 978118.88 mGal, while the minimum gravity measurement value in July 2019 showed a minimum of $978118.62 \mathrm{mGal}$ and a maximum of 978118.88 mGal. Changes in the value (anomaly) gravity during the time interval, there are two possibilities, positive $(0.02$ to $0.29 \mathrm{mGal})$ and negative (-0.11 to $-0.01 \mathrm{mGal})$. Both of these anomaly prices, if they are modeled, an anomaly source will be obtained, which is a positive anomaly caused by subsidence and a negative caused by changes in subsurface density related to dynamics (decrease or increase) of groundwater level.
\end{abstract}

Keywords: microgravity, time-lapse, anomaly, Kota Lama, tourism area 


\section{INTRODUCTION}

The gravity method is one of the oldest methods [1] in geophysics, but its application to anomalous sources near the surface and those related to the environment has not been as intensive as applications for geodynamic or exploration studies in the estimation of relatively large geological structures. This is due to the accuracy of the anomaly still in the order of $\mathrm{mGal}$ or $103 \mu \mathrm{Gal}$. Whereas in terms of gravimeter devices, an accuracy of $10 \mu \mathrm{Gal}$ was achieved in the early 1970s, but the accuracy of the reading is entire $\mu \mu l y$ dependent on the accuracy of the operator because the gravi $\mu$ eter still uses a mechanical reading device.

Time Lapse Micogravity Method (TLMM) is a development of the gravity method, with the fourth dimension being time. The principle of this method is the measurement of the gravity repeatedly both daily, weekly, monthly, and yearly by using a careful gravimeter in the order $\mu \mathrm{Gal}$ and careful measurement of elevation [2]. Any change or difference in the results of the observed gravity in the first period with the next period is called the microgravity anomaly. Changes in the gravity of the observation can be caused by the dynamics around the very point, such as changes in the depth of the groundwater level and subsidence.

In line with the rapid increase in digital technology in the late 1980s, the problem of reading accuracy can be increased by the use of digital reading systems. At the end of 2000, LaCoste $\&$ Romberg released a full digital gravimeter called graviton with an accuracy of $1 \mu \mathrm{Gal}$ and semi-digital gravimeter, which is the development of LaCoste \& Romberg type G, which is equipped with a digital reading system with an accuracy of 1-5 $\mu$ Gal. Early in 2002, Scintrex also issued a full digital called Scintrex Autograv CG5 with an accuracy of $1 \mu \mathrm{Gal}$. With the availability of digital gravimeter systems in full or semi-digital, the constraints associated with tools for observing changes in the gravity field in the order $\mu \mathrm{Gal}$ can be removed.

In this paper, we will describe the microgravity data at the research location in the Kota Lama tourist area. This area has become one of the tourism icons in the city of Semarang. A distinctive feature in this area is the large number of old Dutch heritage buildings that are still used for various purposes. To maintain its preservation, the Semarang city government has made an old cultural heritage protected by law. There is one thing to look out for in this area is subsidence of land. Based on the results of research that has been done, including [3]. The results of previous studies indicate that in the northern area of the city of Semarang, where the Kota Lama area has experienced subsidence of $0.8 \mathrm{~cm} /$ year. Gravity anomaly data will be used to estimate whether it area has experienced subsidence.

This time-lapse microgravity data is used for the purposes mentioned above with the consideration that researches that have been conducted, both in Indonesia and in other parts of the country have been carried out, including [4], [5], [6], [7] and provide information that can be justified by comparing facts in the field.

\section{METHOD}

The method used is known as TLMM. This method can be expressed by the following EQUATION 1. 


$$
\left(g_{o b s(2)}-g_{o b s(1)}\right)=\left(G \int_{0}^{\infty} \int_{-\infty-\infty}^{\infty} \int_{[\infty}^{\infty} \frac{\Delta \rho(\alpha, \beta, \gamma, \Delta t)(z-\gamma)}{\left.(x-\alpha)^{2}+(y-\beta)^{2}+(z-\gamma)^{2}\right]^{3 / 2}} d \alpha d \beta d \gamma\right)+{ }_{c_{1}}\left(h_{2}-h_{1}\right)
$$

EQUATION 1 shows that the difference in the gravity value of the measurement results is due to changes in subsurface mass density that are related to changes in groundwater level and subsidence. On the left hand, segment (gobs (2) - gobs (1)) are the observed gravity measurements for each period 1 and period $2, G$ is the general weighting constant $=6.67 \times 1011$ $\mathrm{m}^{3} / \mathrm{kg}$. $\mathrm{sec}^{2}, \Delta \rho$ changes in mass density, $\alpha, \beta, \gamma$ coordinate of mass density, $\mathrm{x}, \mathrm{y}, \mathrm{z}$ coordinate point, and $\Delta \mathrm{t}$ measurement interval.

It is known that the gravity value in one place is influenced by several things [8], including (1) latitude, (2) elevation, (3) tides, (4) topography, and (5) variations in subsurface mass density. So that the reading of gobs on the surface is related to these five factors, factors 1,2 , and 3 can each be corrected by latitude correction, elevation correction, and tidal correction. Whereas factors 4 and 5 are the target of the anomaly. Therefore separating factors 4 and 5 is a problem that needs to be solved. One technique for this separation is to apply a customized filter [9].

In general, the activities carried out in the field are briefly explained as follows [10]. Given the field conditions, all activities in the field, starting at 0.80 and ending at 17.00. Some of the activities related to the survey are as follows:

\section{(1) Simulation of time-lapse microgravity response}

This simulation aims to determine the magnitude of anomalous time-lapse microgravity to be measured. The response to the gravity anomaly is caused by subsidence and changes in the depth of the groundwater level. Several models of time-lapse microgravity anomaly responses were made at this stage.

\section{(2) Selection of the gravimeter to be used}

TLMM surveys require a very careful gravimeter. As suggested by Wahyudi [11], there are several types of gravimeter that can be used for the purposes of the survey, for example:

a. Gravimeter LaCoste \& Romberg type $\mathrm{D}$ and Type $\mathrm{G}$ which have been equipped with digital allied systems with an accuracy of $1-5 \mu \mathrm{Gal}$.

b. Gravimeter Autograv Scintrex CG 5 with an accuracy of $1 \mu \mathrm{Gal}$.

c. Graviton Gravimeter with an accuracy of $1 \mu \mathrm{Gal}$.

d. Superconducting gravimeter with an accuracy of $0.001 \mu \mathrm{Gal}$

\section{(3) Tidal Correction is measured directly}

This correction is caused by the influence of the force experienced by the Earth due to the mass of the moon and the sun. The price changes periodically depending on the position of the heavenly bodies. This correction is done considering the microgravity response between 
time is generally smaller than the Tidal correction. This correction can be done in two ways, namely: calculating changes in gravity due to changes in the position of the moon and the sun against the Earth (Longman, 1959) and by measuring the gravity directly in the field. In this study, gravity tide correction was measured using a LaCoste \& Romberg G508 gravimeter equipped with feedback factor facilities. This facility allows the gravimeter to be connected to a computer so that measurement data within a specific time interval can be stored and edited as needed. Measurement of gravity for the purpose of this correction is done every time measurement of gravity in the field. For example, the comparison of Tidal corrections using these two methods is shown in FIGURE 1.

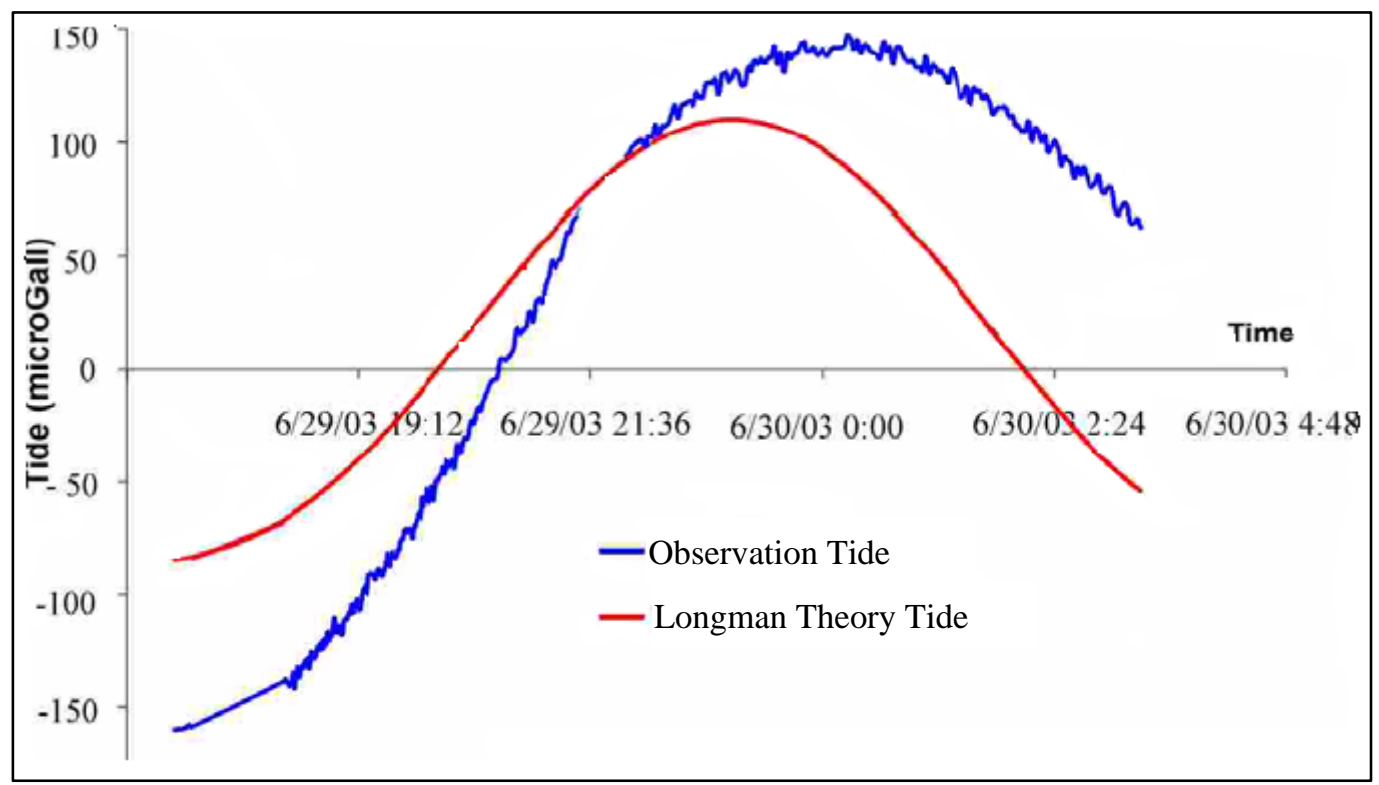

FIGURE 1. Example of Tidal Correction Using the LaCoste \& Romberg G508 Gravimeter and Calculations with the Longman Equation

\section{(4) The order of taking data for each fixed period}

Retrieval of gravity data by looping and the sequence of data retrieval for each measurement period must be fixed. This method aims so that each gravity point gets a relatively similar Drift correction. The point at the beginning of the loop will get a small Drift correction. Instead, the point at the end of the loop will get a large Drift correction.

\section{(5) Selection of a bonding point or microgravity base}

For monitoring purposes using the TLMM, one thing to note is the bonding point. A good tie point must meet the criteria of not experiencing subsidence. There is no decrease in the groundwater level and away from vibrations at that point. In this study, as a bonding point, the Kumudasmoro point is used with close consideration to the base.

\section{(6) Description of the gravity measurement point}

When measuring the gravity of each period, the conditions of the extreme point and its surroundings must be recorded. Things to note are the physical condition of the very point, the 
identity of the identifier of the very point, the height of the water around the very point if the point of gravity is located near a river or sea, the condition of the surrounding soil (wet or dry).

\section{RESULT AND DISCUSSION}

\section{Modeling of Time Lapse Microgravity Anomaly Sources}

In the results section and this discussion will be explained in part by the stages of TLMM, the results of processing and interpretation. As explained in the initial section, it is stated that the source of intermittent microgravity anomalies. The following describes some modeling of microgravity anomaly sources in the form of groundwater level dynamics and subsidence, where the dimensions and physical variables are adjusted to the conditions in the field. The modeling referred to by the model parameters used is a three-layer earth model extending horizontally with the physical properties as follows:

- Layer 1 in the form of clay has a thickness of $10 \mathrm{~m}$ and $\rho=1.9 \mathrm{gr} / \mathrm{cm}^{3}$

- Layer 2 is sand with $\mu=2.0 \mathrm{gr} / \mathrm{cm}^{3}$. Aquifer porosity is $30 \%$, changes in mass density due to a decrease in groundwater level $\Delta \rho=-0.3 \mathrm{gr} / \mathrm{cm}^{3}$

- Layer 3 is clay with a thickness of $10 \mathrm{~m}$ and $\rho=2.1 \mathrm{gr} / \mathrm{cm}^{3}$

Created several conditions of groundwater dynamics and subsidence, including (a) the dimension of subsidence is smaller than the decrease in groundwater level, (b) the dimension of subsidence is greater than the decrease in groundwater level, and (c) the dimension of subsidence and rise in groundwater level is equal.

The results show that case (a) assumed subsidence occurred at coordinates $2500-3500 \mathrm{~m}$, the magnitude of which was at $\mathrm{t} 0=0$ and $\mathrm{t} 1=10 \mathrm{~cm}$. The decrease in groundwater level occurs at coordinates $1000-5000 \mathrm{~m}, 3000-6000 \mathrm{~m}$ and at coordinates $2500-5500 \mathrm{~m}$, each of which is $1.5 \mathrm{~m}$ with the groundwater level at $\mathrm{t} 0=20 \mathrm{~m}$ and $\mathrm{t} 1=21.5 \mathrm{~m}$. The maximum response of gravity anomaly due to subsidence and decrease in the groundwater level of each model was 12,196 $\mu \mathrm{Gal}, 30,706 \mu \mathrm{Gal}$, and 13,376 $\mu$ Gal FIGURE 2.

In case (b), it is assumed that the subsidence occurs at coordinates $2000-4000 \mathrm{~m}$, the magnitude of which is at $\mathrm{t}_{0}=0$ and $\mathrm{t}_{1}=10 \mathrm{~cm}$. The decrease in groundwater level occurs at coordinates $2500-3500 \mathrm{~m}$ groundwater by $1 \mathrm{~m}$ with a groundwater level position at $\mathrm{t}_{0}=30$ $\mathrm{m}$ and $\mathrm{t}_{1}=31 \mathrm{~m}$. The maximum response of gravity anomaly due to subsidence and the decrease in groundwater level is $30,856 \mu \mathrm{Gal}$ FIGURE 3 .

In case (c), it is assumed that subsidence occurs at coordinates $2500-4500 \mathrm{~m}$, the magnitude of $\mathrm{t}_{0}=0$ and $\mathrm{t}_{1}=10 \mathrm{~cm}$, and the increase is assumed to occur at coordinates $2500-4500 \mathrm{~m}$ at $2.5 \mathrm{~m}$ with the groundwater level at $\mathrm{t}_{0}=30$ and $\mathrm{t}_{1}=27.5 \mathrm{~m}$. The maximum response of microgravity anomalies over time due to subsidence and rise in groundwater level is $63,546 \mu \mathrm{Gal}$ FIGURE 4. 

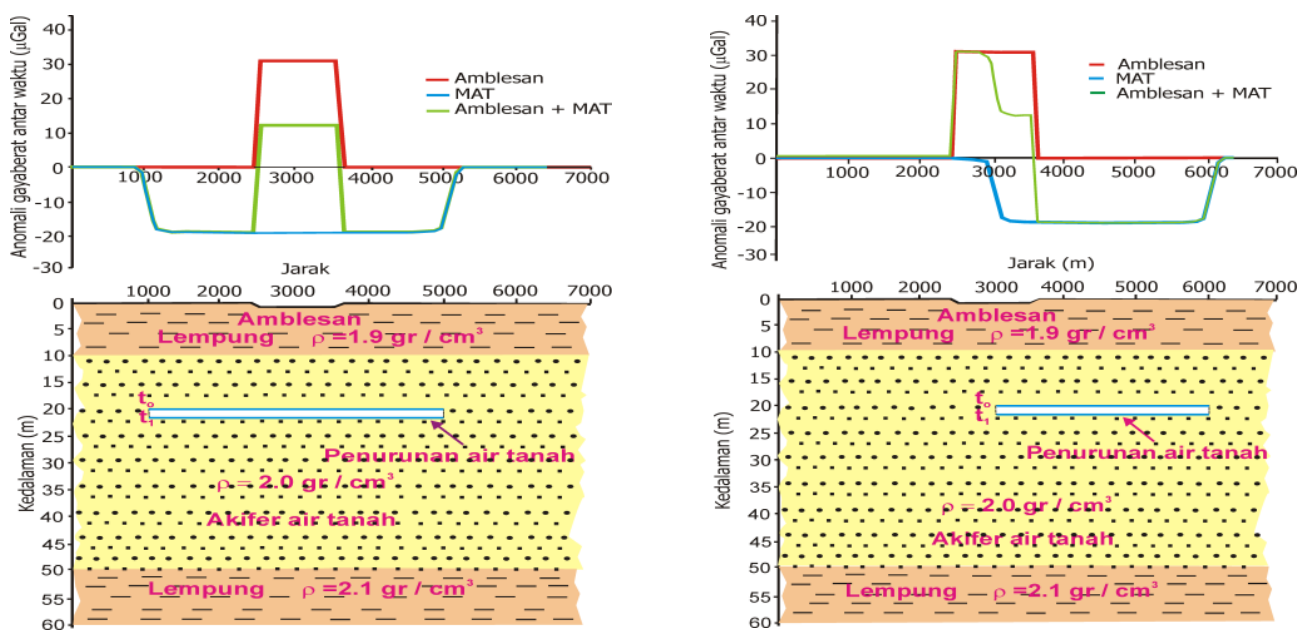

(a)

(b)
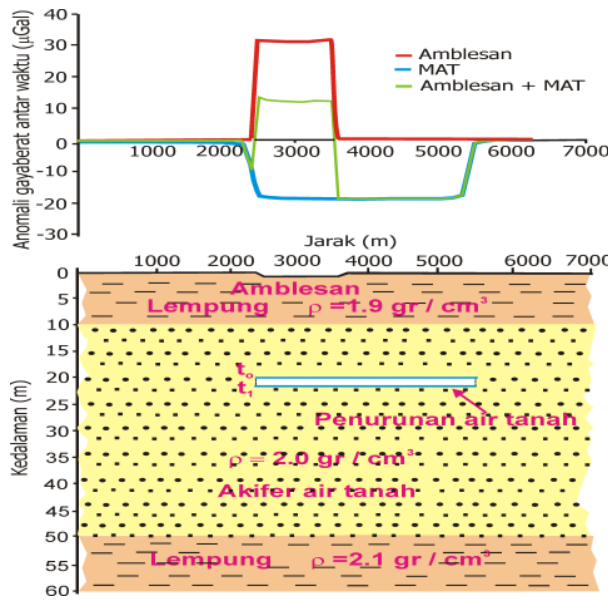

(c)

FIGURE 2. Model of Dimension of Subsidence is Smaller Than a Decrease of Groundwater Level, (a) Position of Subsidence and Aquifer Symmetry, (b) Edge of the Aquifer Is in the Middle of the Subsidence and (c) the Edge of the Aquifer is Parallel to the Tip of the Subsidence 

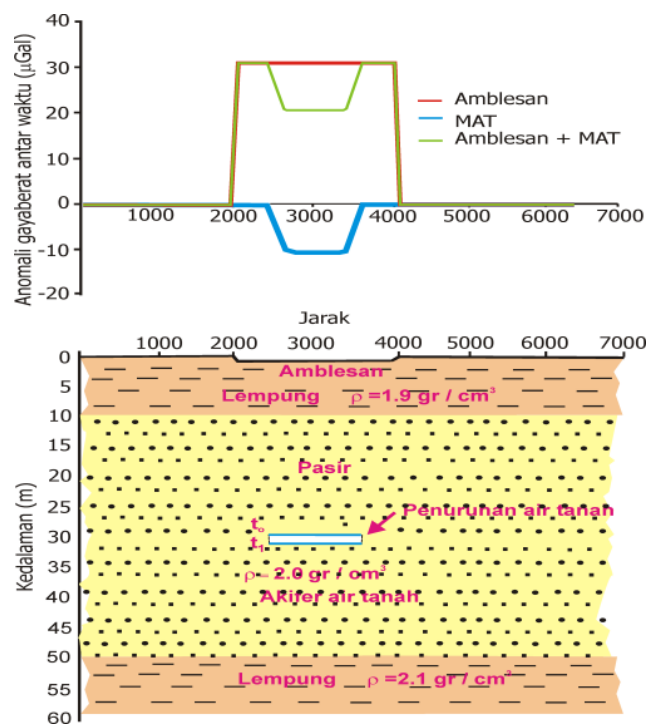

FIGURE 3. Dimension Model Dimensions Greater than Decreasing Groundwater

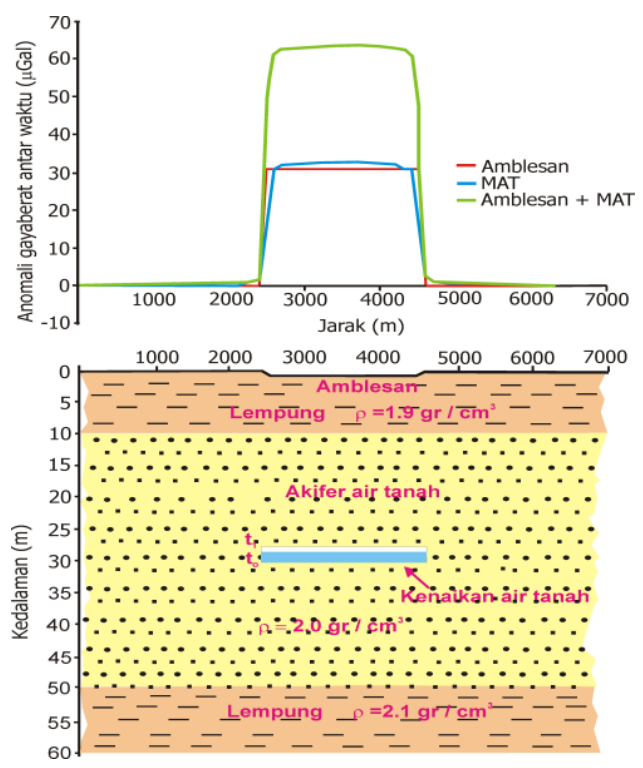

FIGURE 4. A Subsidence Model and an Equal Groundwater Level Increase, The position of the Amblesan and the Raising of the Symmetrical Groundwater

\section{GRA VITY MEASUREMENT VALUE (GoBS)}

The gravity measurement data was carried out in January 2019, which is shown in FIGURE 5a. The gravity measurement value in January with a minimum gravity of $978118.44 \mathrm{mGal}$ and the maximum gravity of $978118.88 \mathrm{mGal}$, while the value of gravity measurement in July 2019 is shown in FIGURE 5b with force a minimum weight of $978118.62 \mathrm{mGal}$ and a maximum weight of $978118.88 \mathrm{mGal}$. 


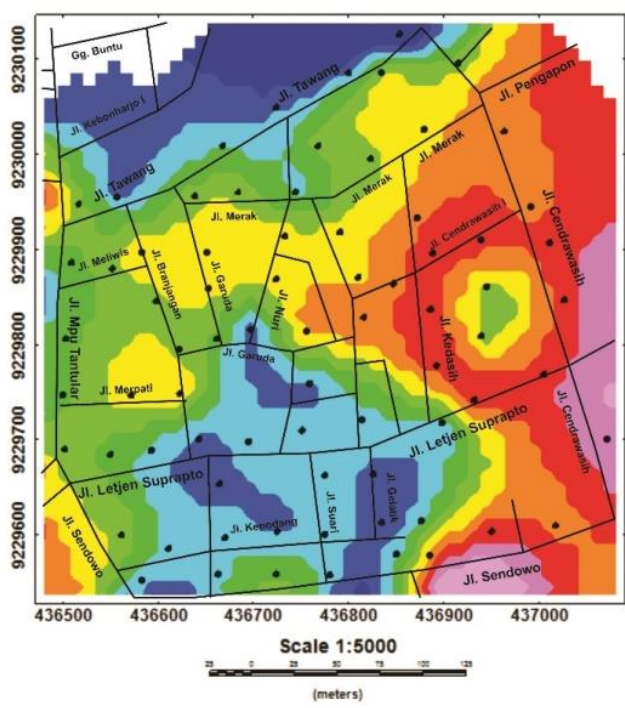

(a)
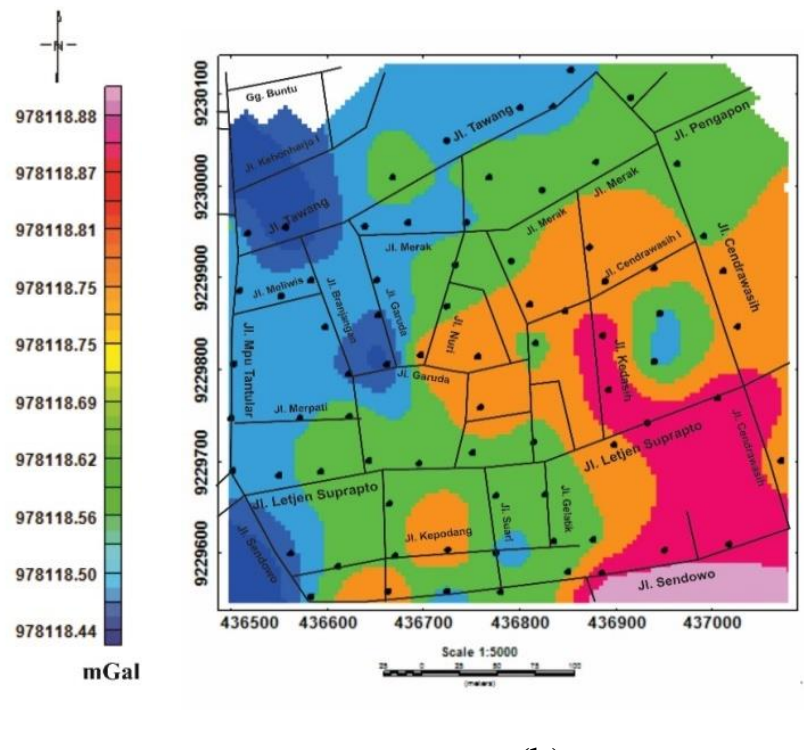

(b)

FIGURE 5. Observation Contour Maps for 2019 in (a) January and (b) the June period

In the picture shows the area that has a low observation gravity value has a higher topography as in the western part of Kota Lama on Mpu Tantular road and north of Tawang Station, which is shown by blue to dark blue images. On the other hand, regions that have high observational gravity values have low topography, as shown almost evenly distributed in the Kota Lama area, which is shown by green to pink imagery. In January 2019 measurement shown in FIGURE 5a and July 2019 measurement shown in FIGURE 5b, it can be seen that the contour pattern is quite significant. Changes in the value of gravity from the period January 2019 to July 2019 can be seen in the following FIGURE 6. This change in gravity value is known as a Time-Lapse Microgravity Anomaly (TLMA).
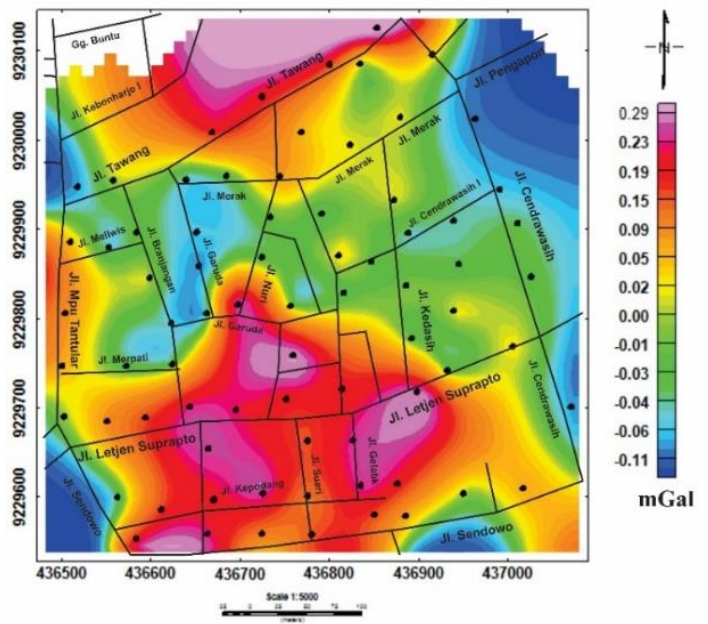

FIGURE 6. Contour Map of TLMA for January - June 2019 Periode 
The gravity measurement data for each period was corrected to obtain a simple Bouguer anomaly contour map in January 2019 and July 2019. The corrections used to reduce the factors that affect the gravity values are buoyancy correction, tidal correction, and Bouguer correction in observed gravity value. Note on the correction not done terrain correction (Terrain Correction). A simple Bouguer anomaly contour map in the January and June 2019 periods is shown in FIGURE 7 below.

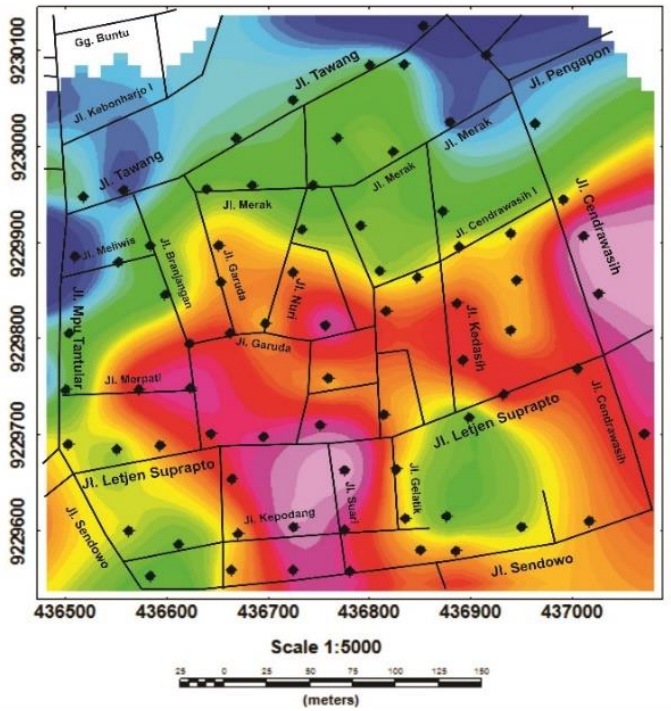

(a)
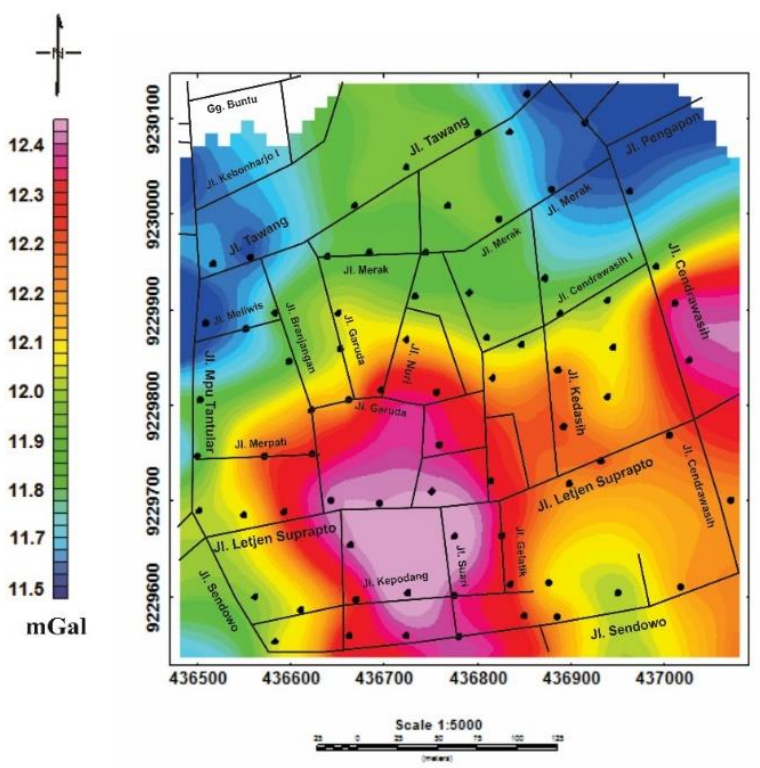

(b)

FIGURE 7. Simple Bouguer Anomaly Contour Map Period (a) January 2019, and Period (b) June 2019

Based on theoretical studies [12], [13], the results of modeling and contour of gravity data, in general, are interesting is the intermittent microgravity anomaly, not the value of gravity for each period. In each period, we only know the value (quantity) and have no physical artist at that time. However, for intermittent micro gravity anomalies, which are the difference between the observed gravity in the June 2019 period and the January 2019 period, there are three possibilities, namely positive (+), negative (-), and zero (0). The three anomaly values are related to EQUATION 1.

TABLE 1. Characteristics of Time Lapse Microgravity Anomalies

\begin{tabular}{lllll}
\hline No. & $\begin{array}{l}\text { Time Lapse } \\
\text { Microgravity }\end{array}$ & subsidence & groundwater level & Evidence \\
\hline 1 & 0 & stable & stable & \\
2 & 0 & down & up & no change \\
3 & 0 & down & down & groubsidence \\
4 & + & down & stable & subsidence \\
5 & + & down & up & subsidence \\
6 & + & stable & up & subsidence \\
7 & + & up & up & subsidence \\
8 & + & down & down & subsidence \\
9 & - & up & stable & groundwater level increasing \\
10 & - & up & up & groundwater level increasing \\
11 & - & up & down & groundwater level decreasing \\
12 & - & down & down & groundwater level decreasing \\
13 & - & stable & down & groundwater level decreasing \\
\hline
\end{tabular}




\section{CONCLUSION}

Based on the results of measurements of intergovernmental microgravity data in Kota Lama Semarang in the periods of January and June 2019, an intermittent microgravity anomaly was found during this time interval. The results quantitatively and qualitatively are shown in FIGURE 6, which shows the dominant anomaly between the 0 (zero) microgravity anomaly in the middle (green to yellow), which indicates no change; positive $(+)$ is dominant in the southern part around the Blenduk church and around it, the north of the surrounding Tawang Station (pink-dark red) which indicates subsidence, and the negative (-) dominant in the east of the survey site (dark blue-dark blue) which indicates a decrease in groundwater level.

The simple Bouguer anomaly contour map, which is the development of the gravity force correction period in January and June 2019 by adding Bouguer correction, shows the value of gravity anomaly in the south is smaller than in the north. This means that the elevation of the measuring points in the south is higher than the elevation of the measurement points in the south.

\section{ACKNOWLEDGMENT}

The author would like to thank DRPM DIKTI through LP2M UNNES for funding this research with the SKIM Basic Research with contract number: 51.18.3 / UN37 / PPK.31 / 2019.

\section{REFERENCES}

[1] K. Mickus, K. (2003). Gravity method: environmental and engineering applications [Online]. Available:

http://www.dot.state.fl.us/statematerialsoffice/Geotechnical/conference/materials/mick us.pdf.

[2] N. Darmawan et al., "Processing and data analysis of time-lapse microgravity due to ground water level changing in baseline stage of CO2 injection," IOP Conf. Ser. Earth Environ. Sci., vol. 318, no. 1, 2019.

[3] S. Soedarsono and R. B. Arief, "Prediksi Amblesan Tanah (Land Subsidence) Pada Dataran Aluvial di Semarang Bagian Bawah," in SEMINAR NASIONAL Kebijakan dan Strategi Pembangunan Infrastruktur Pengembangan Wilayah Berbasis Green Technology, pp. 2-9, 2012.

[4] M. Kobe et al., "Time-lapse gravity and levelling surveys reveal mass loss and ongoing subsidence in the urban subrosion-prone area of Bad Frankenhausen, Germany," Solid Earth, vol. 10, no. 3, pp. 599-619, 2019.

[5] B. Yuwono and M. Awaluddin, "Land Subsidence monitoring 2016 - 2018 analysis using GNSS CORS UDIP and DinSAR in Semarang," KnE Eng., vol. 2019, pp. 95-105, 2019.

[6] A. Setyawan et al., "Detecting Land Subsidence Using Gravity Method in Jakarta and Bandung Area, Indonesia," Procedia Environmental Sciences, vol. 23, pp. 17-26, 2015. 
[7] V. Pazzi et al., "Integrated geophysical survey in a sinkhole-prone area: Microgravity, electrical resistivity tomographies, and seismic noise measurements to delimit its extension," Eng. Geol., vol. 243, pp. 282-293, 2018.

[8] S. Minardi and E. J. Wahyudi, "Analysis and Interpretation of Subsidence Source in Jakarta Using 2009-2010 Time-Lapse,” JTM, vol. 18, no. 4, 2011.

[9] Supriyadi et al., "Modeling response Time Lapse Microgravity Vertical Gradient (TLMVG) anomaly due to fluid volume changes of sub surface and its implementation in Kota Lama Semarang," J. Phys. Conf. Ser., vol. 1321, no. 2, 2019.

[10] Supriyadi et al., "Strategy implementation time lapse microgravity method for monitoring subsidence," AIP Conf. Proc., vol. 1818, March 2017.

[11] E. J. Wahyudi et al., "Designing a genetic algorithm for efficient calculation in timelapse gravity inversion," J. Eng. Technol. Sci., vol. 46B, no. 1, pp. 58-77, 2014.

[12] S. N. E. Wibowo, G. E. Mamuaya, and R. Djamaluddin, "Land Subsidence Analysis of Reclaimed Land using Time-Lapse Microgravity Anomaly in Manado, Indonesia," Forum Geografi, vol. 32, no. 1, pp. 53-63, 2018.

[13] B. Tozer, A. B. Watts and M. C. Daly, "Crustal structure, gravity anomalies, and subsidence history of the Parnaíba cratonic basin, Northeast Brazil," J. Geophys. Res. Solid Earth, vol. 122, no. 7, pp. 5591-5621, 2017. 
